\title{
KAPASITAS POHON NYAMPLUNG (CALOPHYLLUM INOPHYLLUM L.) DAN POHON SPATHODEA (SPATHODEA CAMPANULATA) DALAM MENJERAP DEBU
}

\author{
Alfred Jansen Sutrisno ${ }^{1}$ \\ Gusti Diandasari ${ }^{2}$ \\ Adlia Vidya Rahmandari ${ }^{3}$ \\ ${ }^{1}$ Program Studi Agroteknologi, Fakultas Pertanian dan Bisnis, Universitas Kristen Satya Wacana \\ ${ }^{2,3}$ Program Studi Arsitektur Lanskap, Sekolah Pascasarjana, Institut Pertanian Bogor \\ Penulis korespondensi e-mail: fpb.alfred@uksw.edu
}

\begin{abstract}
The IPB landscape arboretum is a greenbelt on Dramaga Street. Dramaga Street is a lane filled with motorized two-wheeled vehicles, four-wheeled vehicles, even trucks that cause high air pollution, especially types of dust particles. The purpose of this study was to determine the capacity of vegetation as a green belt in absorbing dust. The research method used was purposive sampling, where Nyamplung Tree and Spathodea Tree were used as samples. Leaves on both types of trees will be taken and analyzed to obtain dust absorption capacity. The results of this study explain that the Spathodea Tree has a much larger dust sorption capacity of 0.041-0.043 g/ m2 per day, while the Nyamplung Tree has a dust sorption capacity of 0.023-0.025 g/m2 per day.
\end{abstract}

Keywords: Air pollution, green belt, nyamplung tree, Spathodea tree.

\begin{abstract}
ABSTRAK
Arboretum lanskap IPB merupakan sebuah greenbelt pada Jalan Raya Dramaga. Jalan Raya Dramaga merupakan jalur yang dipadati oleh kendaraan bermotor roda dua, roda empat, bahkan truk yang mengakibatkan tingginya polusi udara khususnya jenis partikel debu. Tujuan penelitian ini ialah untuk mengetahui kapasitas vegetasi sebagai green belt dalam menjerap debu. Metode penelitian yang digunakan ialah purposive sampling, dimana Pohon Nyamplung dan Pohon Spathodea digunakan sebagai sampel. Daun pada kedua jenis pohon tersebut akan diambil dan dianalisis untuk mendapatkan kapasitas jerapan debu. Hasil penelitian ini menjelaskan bahwa Pohon Spathodea memiliki kapasitas jerapan debu yang jauh lebih besar yaitu 0,041-0,043 g/ $\mathrm{m}^{2}$ per hari, sementara Pohon Nyamplung memiliki kapasitas jerapan debu sebesar $0,023-0,025 \mathrm{~g} / \mathrm{m}^{2}$ per hari.
\end{abstract}

Kata kunci: Polusi udara, green belt, pohon nyamplung, pohon spathodea. 


\section{PENDAHULUAN}

Jalan Raya Dramaga merupakan jalur lintas antar kabupaten/kota yang berada di Kabupaten Bogor. Jalur ini menjadi salah satu jalur yang banyak dilintasi oleh kendaraan bermotor baik roda dua maupun roda empat, karena menghubungkan Kota Bogor dan Kabupaten Bogor. Aktifas kendaraan yang begitu tinggi mengakibatkan menurunnya kualitas lingkungan karena partikel debu yang dihasilkan dari kendaraan bermotor. Partikel debu dapat dikatakan sebagai salah satu jenis polutan. Suatu zat dapat disebut polutan pada udara, apabila jumlahnya melebihi jumlah normal, kemudian berada pada waktu yang tidak tepat, dan berada pada tempat yang tidak tepat (Hanafi, 2011). Partikel debu dapat sebagian tertinggal di udara dan sebagian lagi terbawa angin (Department for Environmental Food \& Rural Affairs, 2014). Hal ini dapat memberikan dampak yang buruk bagi kesahatan manusia ketika dihirup. Partikel debu yang memiliki ukuran 5-10 mikron dapat masuk ke saluran napas atas, 3-5 mikron dapat masuk ke saluran napas tengah, 1- 3 mikron dapat masuk mencapai pembuluh di alveoli, 0,5-1 mikron dapat menempel di alveoli, dan partikel debu berukuran 0,1-0,5 mikron dapat melayang di atas alveoli (Depkes, 2014). Hal tersebut membuktikan bahwa partikel debu bisa mengakibatkan gangguan pernapasan bagi manusia.

Salah satu peranan atau manfaat vegetasi ialah untuk mereduksi polutan udara. Keberadaan vegatasi pada bahu jalan dapat dikatakan sebagai green belt atau jalur hijau. Green belt ialah suatu ruang atau tapak yang membatasi aktifitas antara ruang yang satu dengan ruang lainnya sehingga tidak saling mengganggu (Marmi, 2016; Susanto, 2018). Dengan demikian lanskap jalan raya atau jalan tol tentunya harus memenuhi aspek efisiensi, keamanan, kenyamanan, serta penampilan yang menarik untuk memperlancar sirkulasi kendaraan dan mengantisipasi dampak - dampak yang ditimbulkannya seperti polusi udara, kebisingan, panas, dan ketidaknyamanan.

Arboretum merupakan suatu area yang berfungsi untuk pelestarian keanekaragaman hayati, dimana elemen utamanya ialah berbagai jenis pohon. Arboretum juga dapat dijadikan sebagai fasilitas penelitian, pendidikan, dan pengembangan (Napolion dkk, 2015). Arboretum Lanskap IPB menjadi salah satu green belt pada Jalan Raya Dramaga, karena letaknya yang menjadi pembatas antara lanskap jalan dengan lanskap kampus IPB (Gambar 1). Oleh sebab itu, Arboretum Lanskap IPB dijadikan sebagai tempat penelitian. Arboretum Lanskap IPB merupakan suatu ruang yang menjadi tempat koleksi tanaman. Namun pada penelitian ini hanya mengambil dua jenis pohon yang dijadikan 
sampel yaitu Pohon Nyamplung (calophyllum inophyllum l.) dan Pohon Spathodea (spathodea campanulata). Tujuan penelitian ini ialah untuk mengetahui kemampuan Pohon Nyamplung dan Pohon Spathodea dalam menjerap debu.

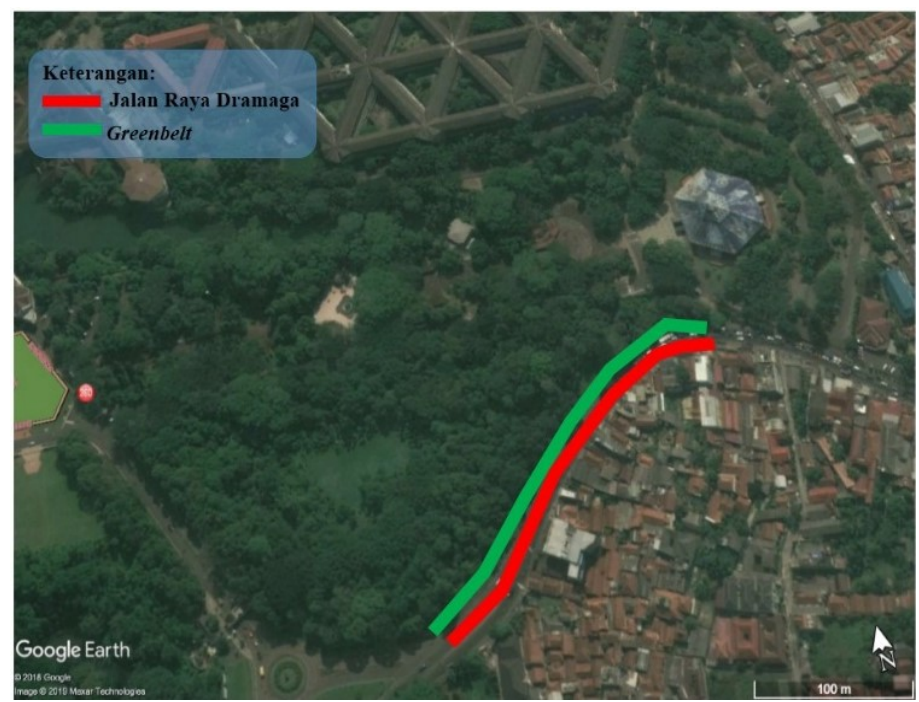

Gambar 1. Lokasi Penelitian

Sumber: Googleearth, Hasil Olahan, 2019

\section{METODOLOGI}

Penelitian ini dilakukan dengan menggunakan metode purposive sampling, dimana Pohon Nyamplung dan Pohon Spathodea yang dijadikan sampel merupakan pohon yang berbatasan langsung dengan Jalan Raya Dramaga (Nasrullah, 2008). Teknik Pengumpulan data dilakukan dengan cara (1) pohon yang dijadikan sampel masing - masing berjumlah dua dan (2) daun Pohon Nyamplung dan Pohon Spathodea yang diambil adalah daun dewasa, dimana lokasi pengambilan daun memiliki jarak ketinggian $3 \mathrm{~m}$ dari permukaan tanah dengan posisi yang menghadap jalan, masing-masing seberat 20 gram (Gambar 2).

Lokasi pengambilan sampel daun

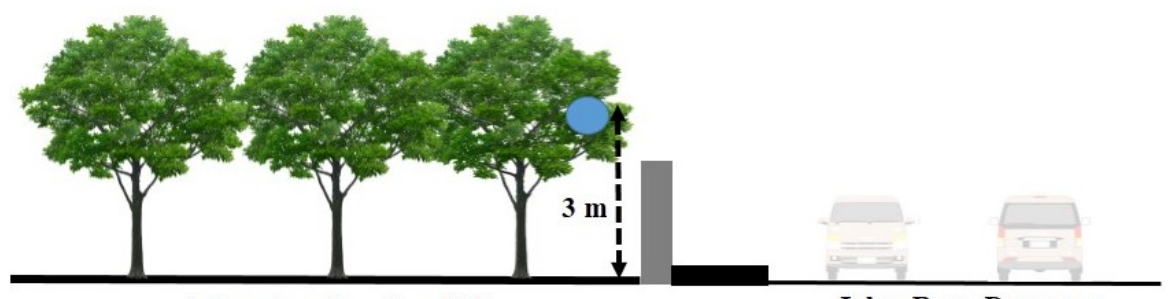

Arboretum Lanskap IPB

Jalan Raya Dramaga

Gambar 2. Lokasi Pengambilan Sampel Daun Sumber: Dokumen pribadi, 2019 
Analisis data yang digunakan pada penelitian ini ialah (1) mengukur luas daun dengan metode gravimetri (Formula 1), (2) menghitung kapasitas daun menjerap debu (Formula 2), dan (3) menghitung kapasitas adsorpsi partikel harian (Formula 3) (Lilianto, 2018).

Luas daun $\left(\mathrm{cm}^{2}\right)=\frac{\text { Beral cupy daun pada kertas }}{\text { berat kertas } 10 \times 10} \times 100$

Kapasitas daun menjerap debu $=\frac{\text { (Borat beakertdebu)-(Berat beaker awal) }}{\text { luas dawn }}$

$\mathrm{P}=\left[\frac{\mathrm{Pn}-\mathrm{P}(\mathrm{n}-1)}{n-1}\right] \mathrm{X} \mathrm{d} \quad \ldots \mathrm{g} / \mathrm{m}^{2} /$ hari

Keterangan : P: kapasitas adsorpsi partikel harian

$\mathrm{n}$ : banyak pengamatan,

P (n-1): sampel kapasitas adsorpsi partikel pada (n-1)

d: interval sampling

\section{HASIL DAN PEMBAHASAN}

\section{A. Pengukuran Luas Daun dan Berat Beaker}

Pengukuran luas daun merupakan hasil pertama yang harus diketahui dalam menghitung kapasitas pohon dalam menjerap debu. Hasil penelitian ini menunjukkan bahwa luas daun pohon spathodea jauh lebih besar jika dibandingkan dengan pohon nyamplung baik pada sampling 1 dan sampling 2 (Tabel 1).

Tabel 1. Luas Daun

\begin{tabular}{|c|c|c|}
\hline \multirow{2}{*}{ Jenis Pohon } & \multicolumn{2}{|c|}{ Luas Daun $\mathbf{( c m}^{2}$ ) } \\
\cline { 2 - 3 } & Sampling 1 & Sampling 2 \\
\hline Nyamplung 1 & 321,43 & 211,68 \\
\hline Nyamplung 2 & 310,71 & 202,44 \\
\hline Spathodea 1 & 790,47 & 388,92 \\
\hline Spathodea 2 & 577,38 & 421,68 \\
\hline
\end{tabular}

Sumber: Analisis Peneliti, 2019

Pengukuran selanjutnya ialah pengukuran berat beaker yang dilakukan menggunakan timbangan digital dimana pengukuran ini dilakukan dengan 2 perlakuan yang berbeda yaitu pada saat sebelum penguapan dan setelah penguapan (Tabel 2). Perlakuan setelah penguapan dilakukan dengan cara memasukkan seluruh gelas beaker yang berisi air dari cucian daun kedalam oven dengan suhu $80^{\circ} \mathrm{C}$ selama 2 x 24 jam kemudian beaker yang telah dikeringkan ditimbang maka hasil pengukuran yang didapat disebut berat beaker setelah penguapan. 
Tabel 2. Hasil Pengukuran Berat Beaker

\begin{tabular}{|l|c|c|c|c|}
\hline \multirow{2}{*}{ Jenis Pohon } & \multicolumn{3}{|c|}{ Pengukuran Berat Beaker (gram) } \\
\cline { 2 - 5 } & \multicolumn{2}{|c|}{ Sampling 1 } & \multicolumn{2}{c|}{ Sampling 2 } \\
\cline { 2 - 5 } & $\begin{array}{c}\text { Sebelum } \\
\text { Penguapan }\end{array}$ & $\begin{array}{c}\text { Sesudah } \\
\text { Penguapan }\end{array}$ & $\begin{array}{c}\text { Sebelum } \\
\text { Penguapan }\end{array}$ & $\begin{array}{c}\text { Sesudah } \\
\text { Penguapan }\end{array}$ \\
\hline Nyamplung 1 & 62,35 & 62,36 & 69,72 & 69,73 \\
\hline Nyamplung 2 & 60,47 & 60,48 & 62,40 & 62,41 \\
\hline Spathodea 1 & 61,42 & 61,44 & 62,46 & 62,48 \\
\hline Spathodea 2 & 69,74 & 69,74 & 62,11 & 62,13 \\
\hline
\end{tabular}

Sumber: Analisis Peneliti, 2019

\section{B. Kapasitas Daun Menjerap Debu}

Pada sampling 1 pohon nyamplung memiliki kapasitas jerapan debu yang jauh lebih besar jika dibandingkan dengan pohon spathodea. Pada sampling 2 kedua pohon memiliki kapasitas jerapan yang hampir sama walaupun pada pohon spathodea 1 kapasitas jerapan debu mencapai $0,541 \mathrm{~g} / \mathrm{m}^{2}$ (Tabel 3).

Tabel 3. Hasil Pengukuran Kapasitas Daun Menjerap Debu

\begin{tabular}{|l|c|c|}
\hline \multirow{2}{*}{ Jenis Pohon } & \multicolumn{2}{|c|}{ Kapasitas Daun Menjerap debu $\left(\mathbf{g} / \mathbf{m}^{\mathbf{2}}\right)$} \\
\cline { 2 - 3 } & Sampling 1 & Sampling 2 \\
\hline Nyamplung 1 & 0,311 & 0,472 \\
\hline Nyamplung 2 & 0,321 & 0,494 \\
\hline Spathodea 1 & 0,253 & 0,541 \\
\hline Spathodea 2 & 0,173 & 0,474 \\
\hline
\end{tabular}

Sumber: Analisis Peneliti, 2019

\section{Hasil Kapasitas Jerapan Debu Per Hari}

Pada perhitungan kapasitas jerapan debu per hari, pohon yang memiliki kapasitas jerapan debu per hari paling tinggi ialah Pohon Spathodea yaitu bisa mencapai $0,043 \mathrm{~g} / \mathrm{m}^{2}$ dan tidak berbeda jauh dengan Pohon Spathodea lainnya. Kapasitas jerapan debu per hari dari Pohon Nyamplung hanya bisa mencapai $0,025 \mathrm{~g} / \mathrm{m}^{2}$ (Tabel 4).

Tabel 4. Kapasitas Jerapan Debu Per Hari

\begin{tabular}{|l|c|}
\hline Jenis Pohon & Kapasitas jerapan debu per hari $\left(g_{\mathbf{m}^{\mathbf{2}}}\right)$ \\
\hline Nyamplung 1 & 0,023 \\
\hline Nyamplung 2 & 0,025 \\
\hline Spathodea 1 & 0,041 \\
\hline Spathodea 2 & 0,043 \\
\hline
\end{tabular}

Sumber: Analisis Peneliti, 2019

\section{Hasil Kapasitas jerapan debu per tanaman per hari}

Untuk mengetahui kapasitas jerapan debu per tanaman per hari, hal yang pertama yang harus dilakukan ialah mengetahui jari-jari tajuk. Hasil perhitungan jari-jari tajuk menunjukkan bahwa Pohon Spathodea 1 memiliki jari-jari tajuk yang lebih besar yaitu 3 meter, sementara untuk Pohon Nyamplung yang paling besar ialah 1,5 meter (Tabel 5). 
Tabel 5. Jari-jari Tajuk

\begin{tabular}{|l|c|}
\hline Jenis Pohon & Jari-jari tajuk $(\boldsymbol{m})$ \\
\hline Nyamplung 1 & 1,5 \\
\hline Nyamplung 2 & 1,25 \\
\hline Spathodea 1 & 3 \\
\hline Spathodea 2 & 1,25 \\
\hline
\end{tabular}

Sumber: Analisis Peneliti, 2019

Kemudian dari hasil perhitungan jari-jari tajuk, hal kedua yang perlu dilakukan ialah luas tajuk. Luas tajuk Pohon Spathodea 1 merupakan luas tajuk yang paling besar yaitu 113,04 meter dan diikuti oleh Pohon Nyamplung 1 (28,26 meter). Pohon Nyamplung 2 dan Pohon Spathodea 2 memiliki luas tajuk yang sama yaitu 19,625 meter (Tabel 6).

Tabel 6. Luas Tajuk

\begin{tabular}{|l|c|}
\hline Jenis Pohon & Luas tajuk $\left(\mathbf{m}^{\mathbf{2}}\right)$ \\
\hline Nyamplung 1 & 28,26 \\
\hline Nyamplung 2 & 19,625 \\
\hline Spathodea 1 & 113,04 \\
\hline Spathodea 2 & 19,625 \\
\hline
\end{tabular}

Sumber: Analisis Peneliti, 2019

Pohon Spathodea 1 yang memiliki luas tajuk yang lebih luas memiliki kapasitas jerapan debu per tanaman per hari lebih besar jika dibandingkan dengan yang lainnya yaitu sebesar 4,634 g namun jika dilihat dari kapasitas jerapan debu per hari justru Pohon Spathodea 1 jauh lebih kecil dibandingkan dengan Pohon Spathodea 2. Perbedaan ini bisa terjadi diakibatkan pengaruh lokasi pohon yang berbeda (Hermawan, et al., 2007).

Tabel 7. Kapasitas Jerapan Debu Per Tanaman Per Hari

\begin{tabular}{|l|c|c|c|}
\hline Jenis Pohon & $\begin{array}{l}\text { Luas tajuk } \\
\left(\boldsymbol{m}^{2}\right)\end{array}$ & $\begin{array}{l}\text { Kapasitas jerapan debu } \\
\text { per hari }\left(\boldsymbol{g}_{/} / \boldsymbol{m}^{\mathbf{2}}\right)\end{array}$ & $\begin{array}{l}\text { Kapasitas jerapan debu per } \\
\text { tanaman per hari (g) }\end{array}$ \\
\hline Nyamplung 1 & 28,26 & 0,023 & 0,649 \\
\hline Nyamplung 2 & 19,625 & 0,025 & 0,490 \\
\hline Spathodea 1 & 113,04 & 0,041 & 4,634 \\
\hline Spathodea 2 & 19,625 & 0,043 & 0,843 \\
\hline
\end{tabular}

Sumber: Analisis Peneliti, 2019

\section{KESIMPULAN DAN SARAN}

\section{A. Kesimpulan}

Pohon Spathodea memiliki kapasitas jerapan debu yang jauh lebih besar dibandingkan dengan Pohon Nyamplung hal ini dipengaruhi oleh luas tajuk dan jari-jari tajuk. Luas tajuk dan jari-jari tajuk pada Pohon Spathodea jauh lebih besar dibandingkan 
dengan pohon Nyamplung. Jenis pohon yang paling direkomendasikan sebagai green belt untuk menjerap debu ialah Pohon Spathodea. Menurut Hakim (2017), Pohon yang berdaun lebar di sepanjang jalan Dramaga, Kab. Bogor memiliki kemampuan menjerap debu lebih baik daripada pohon yang berdaun kecil. Bahkan, Pohon dapat menjerap atau menghapus polutan 1261,4 ton di Beijing (Yang, et al., 2005).

\section{B. Saran}

Terdapat beberapa saran yang bisa diberikan jika melihat hasil penelitian ini, yaitu;

1. Perlu adanya perhitungan distribusi suhu secara vertikal, karena suhu memiliki peranan penting dalam penyebaran debu.

2. Perlu dilakukannya sebuah analisis terhadap pengaruh jumlah kendaraan dengan kapasitas jerapan debu per hari sebuah vegetasi.

\section{DAFTAR PUSTAKA}

Department for Environmental Food \& Rural Affairs. (2014). Effects of Air Pollution. Diakses dari uk- air.defra.gov.uk/air-pollution/effects.

Depkes RI. (2014). Parameter Pencemar Udara dan Dampaknya Terhadap Kesehatan. Diakses dari www.depkes.go.id/downloads/udara.

Hakim, L., Putra, P. T., Zahratu, A., L. (2017). Efektifitas Jalur Hijau dalam Mengurangi Polusi Udara oleh Kendaraan Bermotor. Jurnal Arsitektur. 16(1), 91-100.

Hanafri., Kartika, S. (2011). Analisis Manfaat Kanopi Pohon Dalam Mereduksi Polutan Udara Menggunakan Program Citygreen Di Jalan Raya Padjajaran. Kota Bogor [skripsi]. Bogor (ID): Institut Pertanian Bogor.

Hermawan, R., Kusmana, C., Nasrullah, N., Prasetyo, L. B. (2011). Jerapan Debu dan Partikel Timbal $(\mathrm{Pb})$ oleh Daun Berdasarkan Letak Pohon Dan Posisi Tajuk: Studi Kasus Jalur Hijau Acacia Mangium Jalan Tol Jagorawi. Media Konservasi, 16(3), 101-107.

Lilianto, G. H., Dewi, N. K., Martuti, N. K. T. (2018). Kandungan Timbal, Debu di Udara dan Daun Tanaman Peneduh di Kota Semarang. Life Science, 7(2).

Marmi. (2016). Ruang Terbuka Hijau (RTH) Kota Surabaya sebagai Wahana Peningkatan Kemampuan Dasar Sistimatik Tumbuhan. Inovasi, 18(1), 72-79.

Napolion, H., Sribudiani, E., Arlita, T. (2015). Pemahaman Pengunjung terhadap Arti dan Fungsi Arboretum Universitas Riau. Jurnal Online Mahasiswa Fakultas Pertanian, 2(2). 
Nasrullah, N. (2008). Jenis, Sumber, dan Metode Pengukuran Bahan Pencemar Udara (Polutan). Bahan kuliah program studi Arsitektur lanskap Sekolah Pascasarjana. Bogor (ID): Institut Pertanian Bogor.

Susanto J. P., Komarawidjaja, W. (2018). Pembangunan Green Belt sebagai Antisipasi Pencemaran Udara Industri Pupuk Di Kalimantan Timur. Jurnal Teknologi Lingkungan. 19(2).

Yang, J., McBride, J., Jinxing, Z., Zhenyuan, S., 2005, The Urban Forest in Beijing and Its Role in Air Pollution Reduction. Journal Urban Forestry \& Urban Greening, 3, 6578. 